\title{
NAAR EEN VENNOOTSCHAPSKAMER?
}

\author{
door J. M. Vecht
}

\section{Par. 1. Inleiding}

In 1953 werd door de Wiardi Beckmanstichting een Commissie ingesteld, die tot taak had de wenselijkheid en mogelijkheid van een herziening van het vennootschapsrecht te bestuderen. In het bijzonder dienden aspecten van medezeggingschap van de factor arbeid in het ondernemingsbeleid te worden bezien. Het rapport van genoemde commissie is nu onlangs in druk verschenen. ${ }^{1}$ ) Daarin wordt $0 . \mathrm{m}$. geadviseerd tot instelling van een tripartite raad van Commissarissen over te gaan bij naamloze vennootschappen met een aandelenkapitaal van meer dan $f 10$ miljoen of met meer dan 200 werknemers. ${ }^{2}$ ) In deze Raad van Commissarissen zou $1 / 3$ van het aantal commissarissen door de aandeelhouders, $1 / 3$ door de overheid en $1 / 3$ door de ondernemingsraden - via de vakbonden - worden benoemd. Daarnaast wil de commissie, teneinde vollediger inzicht in de gang van zaken van de naamloze vennootschap aan vermogensverschaffers en potentiële beleggers te verschaffen, nieuwe voorschriften in de wet op de n.v. met betrekking tot de jaarverslaggeving zien opgenomen. De instelling van een toezichthoudend orgaan, een Vennootschapskamer, wordt daarbij bepleit.

De door de commissie gedane aanbevelingen ter versterking van de factor arbeid in het ondernemingsbeheer en ter versterking van de positie van de - thans veelal onmondige - aandeelhouders zullen hier, al zijn er vele bezwaren tegen aan te voeren, niet besproken worden. Dat zou een uitvoerige bespreking van het vrij omvangrijke rapport eisen, die onvermijdelijk in het politieke vlak wordt getrokken. Ik wil mij hier vooral bezig houden met de idee van de Vennootschapskamer. Tegen de achtergrond van een summiere historische beschouwing over het begrip „Vennootschapskamer" zal met name de vraag worden besproken, of de instelling van een Vennootschapskamer van belang geacht kan worden en in het bevestigende geval, of een dergelijke Kamer realiseerbaar is op de door de commissie gedachte wijze. Over de positie van de accountant met betrekking tot een dergelijke instelling zullen dan tot slot enige opmerkingen worden gemaakt. Ik meen de bespreking van een Vennootschapskamer mede te kunnen motiveren gezien de belangstelling, die heden ten dage voor een dergelijke figuur bestaat en ruimer gezien, in verband met de roep om een herziening van het vennootschapsrecht, die van verschillende zijden wordt gehoord. ${ }^{3}$ )

\section{Par. 2. De ontwikkeling van de opvattingen over een Vennootschapskamer}

De idee, om tot instelling van een lichaam over te gaan dat mede tot taak heeft controle op naamloze vennootschappen ten aanzien van publicatieplicht, is geenszins nieuw. Gezien het feit, dat de moderne publieke naamloze vennootschap eigenlijk eerst sinds kort bestaat, wil dat niet zeggen dat men er ver in de geschiedenis voor kan teruggaan. Vermoedelijk is, in Nederland althans, de gedachte aan een Vennootschapskamer eerst bij de behandeling van de wet op de naamloze vennootschap van 2 juli 1928 gerezen. In het parlementaire jaar 1926-1927 is door het

1) „De hervorming van de onderneming”, publicatie nr. 4 in de door de W.B.-stichting uitgegeven serie „Maatschappelijke vraagstukken”, Amsterdam 1959.

2) In feite zijn de betreffende begrenzingen verfijnder aangebracht; in het kader van dit opstel behoeft e.e.a. hier niet in den brede te worden besproken.

3) In de Troonrede 1959 werd medegedeeld, dat de Regering zich zal doen voorlichten door een staatscommissie over de vraag in hoeverre een herziening van het vennootschapsrecht gewenst is. 
toenmalige parlementslid van de Rooms Katholieke Staatspartij, Mr. J. R. H. van Schaik, de instelling van een dergelijk instituut bepleit. Deze ging er van uit, dat het bedrijfsleven niet aan publiekrechtelijke inmenging onttrokken kon blijven. Om het publiek te vrijwaren tegen de gevaren van een „malafide, roekeloze, onverantwoordelijke bedrijfsgestie" achtte hij instelling van een Vennootschapskamer dringend geboden. Dit zou dan een overheidslichaam moeten zijn met bevoegdheden, welke ten dele aan aandeelhouders zouden moeten worden onttrokken, zoals het enquêterecht. Het algemeen belang zou door een dergelijk lichaam worden bevorderd, enerzijds doordat het beter dan de aandeelhouders in staat zou zijn toezicht op het beleid van de naamloze vennootschap uit te oefenen, anderzijds door de naamloze vennootschap te beschermen tegen eventuele ongerechtvaardigde verlangens van aandeelhouders. Met bedrijfspolitiek in engere zin zou de Vennootschapskamer zich niet mogen inlaten. Gewezen werd op het bestaan van de Verzekeringskamer, al wilde Van Schaik de Vennootschapskamer niet de vergaande bevoegdheden van deze geven. De Vennootschapskamer diende ervoor te zorgen dat de formele voorschriften en de publiciteit met betrekking tot de naamloze vennootschap tot hun recht zouden komen. Daarnaast diende de Kamer over bevoegdheden te beschikken om bij voorgenomen of gepleegde onregelmatigheden te kunnen ingrijpen ten faveure van aandeelhouders, crediteuren en het publiek.

Het denkbeeld van Van Schaik werd door Prof. Mr. W. H. Drucker critisch besproken. Deze stelde een voorlopig ontwerp op van de taken die de Vennootschapskamer zou dienen te verrichten; o.m. zou de Vennootschapskamer de in het ontwerp van wet op de naamloze vennootschap aan de accountant toegedachte taak kunnen overnemen, dan wel bij publieke naamloze vennootschappen naast de accountant optreden met de Rijksaccountantsdienst te zijner beschikking. Emissieprospecti zouden aan de Vennootschapskamer dienen te worden voorgelegd. Evenwel werd het op die wijze geconcretiseerde denkbeeld van een Vennootschapskamer door Prof. Drucker verworpen. Als alternatief stelde hij verdere ontwikkeling van de accountantscontrole op de naamloze vennootschap en wettelijke regeling van dit beroep voor. De wet op de naamloze vennootschap van 2 juli 1928 nam echter noch Van Schaik's, noch Drucker's opvattingen over. Minister Donner stelde zich toentertijd op het standpunt, dat om misbruiken tegen te gaan en waarborgen voor derden te verschaffen, gekozen kon worden tussen overheidsinmenging of regeling van de inwendige machtsverhouding der naamloze vennootschap. Hij prefereerde het laatste. Hij nam wel stelling tegen oligarchische clausules; van versterking van de rechten van aandeelhouders verwachtte hij hiertegen echter alle heil.

Het heeft tot 1952 geduurd voor opnieuw voor een groot publiek de wenselijkheid van een Vennootschapskamer werd bepleit. ${ }^{4}$ ) In een opzienbarend betoog geschiedde dit door Mr. P. Sanders. Hij trok een parallel met de Verzekeringskamer en verwees naar de werkzaamheden van de Securities and Exchange Commission in de Verenigde Staten van Amerika. Zocht Drucker de oplossing uitsluitend in het versterken van de positie van de accountants, Sanders wil die versterking wel invoeren maar naast het instellen van een Vennootschapskamer. Hij motiveert het instellen van die Kamer door te verwijzen naar de ongewenste praktijken die onder de werking van de wet van 1928 mogelijk zijn. In de eerste plaats

4) Mr. P. Sanders, „Verantwoording van het bestuur van de publieke naamloze vennootschap" in de bundel Rechtskundige Opstellen, aangeboden aan Prof. Mr. R. P. Cleveringa, Zwolle 1952, blz. $329 / 363$. 
wijst hij op het veelvuldig voorkomen van een N.V. Gemeenschappelijk of Nationaal bezit van aandelen in een werk-naamloze vennootschap. In een dergelijke N.V. Gemeenschappelijk Bezit berust de macht meestal uitsluitend bij directie en commissarissen van de werk-n.v. De aandelen van de werk-n.v. worden n.l. omgeruild in die van de holding; door het bezit van prioriteitsaandelen of een meerderheidspakket van aandelen van de holding kan de leiding van de werk-n.v. zichzelf décharge verlenen voor het in de werk-n.v. gevoerde beleid. Naast deze ongewenste figuur wijst Mr. Sanders in de tweede plaats op die van het Administratiekantoor. Het - meestal kleine - aandelenkapitaal van het Administratiekantoor is in handen van directie en commissarissen van de werk-n.v. De aandelen van de werk-n.v. worden omgewisseld in certificaten van aandelen in de werk-n.v., die het Administratiekantoor plaatst. Door het niet-royeerbaar maken van deze certificaten is de zeggenschap van aandeelhouders der werk-n.v. uitgeschakeld. Beide middelen, de N.V. Gemeenschappelijk Bezit en het Administratiekantoor acht $M r$. Sanders ,,in flagrante strijd met de geest en strekking van onze betrekkelijk nieuwe wet op de naamloze vennootschap".

$\mathrm{Na}$ een betoog te hebben gewijd aan de werking van de Securities and Exchange Commission in de Verenigde Staten, waar krachtens een aantal wetten tegen allerlei misstanden zoals bovengenoemde buiten-statutaire constructies wordt opgetreden, bepleit hij in een paragraaf over het ,ius constituendum" het instellen van een Vennootschapskamer. Deze dient in hoofdzaak te zorgen voor volledige publiciteit omtrent ter beurze genoteerde vennootschappen. Dit houdt dan o.m. in het houden van toezicht op het emissieprospectus van de naamloze vennootschap, hetzij bij oprichting - zoals reeds Drucker noodzakelijk achtte - hetzij bij latere emissies. Deze door optreden van de Vennootschapskamer gewaarborgde openbaarheid zou preventief vermogen te werken. Hij wenst zo volledig mogelijke inlichtingen van de vennootschap, zowel aan de Vennootschapskamer (jaarlijks, eventueel drie-maandelijks) als door middel van jaarstukken, tussentijdse publicaties en emissieprospecti aan het publiek. Het medebesturen van de aan de controle van de Vennootschapskamer onderworpen lichamen vindt hij - evenals Van Schaik - verwerpelijk; wel wenst hij de Vennootschapskamer desgevraagd of eigener beweging aan de Ministers te laten adviseren over vragen op vennootschapsgebied. Tenslotte wil Sanders, teneinde de Vennootschapskamer behoorlijk te doen functionneren, de instelling daarvan gepaard doen gaan met een versterking van de positie van de accountant en met de nodige waarborgen van een behoorlijke beroepsuitoefening door deze. De Vennootschapskamer zal de accountantscontrole bij naamloze vennootschappen niet overnemen, wel richtlijnen ten aanzien van de accountantscontrole geven.

Van verschillende zijden werd kritiek gehoord op deze, in feite gematigde, voorstellen. Bij de herdenking van de inwerkingtreding van de Wet op de Naamloze Vennootschap werd in 1953 o.m. door Prof. Mr. P. W. Kamphuisen en Mr. W. L. Haardt gewezen op het gevaar voor verder gaande overheidsbemoeiing en de vermindering van het verantwoordelijkheidsgevoel, dat instelling van een Vennootschapskamer met zich mee zou kunnen brengen. ${ }^{5}$ ) Kamphuysen vraagt verder naar het bewijs, dat een dergelijke Kamer nodig zou zijn; Haardt meent, dat de controle op een desnoods verscherpte verslaggevingsplicht wel bij de huidige Kamers van Koophandel kan worden gelegd. Werden deze kritische uitingen nog

5) Prof. Mr. P. W. Kamphuysen, „Het oligarchisch karakter der naamloze vennootschap", N.V. XXX, febr./mrt. 1953, pag. 202 en Mr. W. L. Haardt, „Hervormingswensen”, N.V. XXX, febr./mrt 1953, pag. 231/232. 
min of meer ,en passant" te berde gebracht, in 1954 opent $M r$. A. Schadee in een artikel in de „Naamloze Vennootschap” een frontale aanval op de desiderata van Sanders. ${ }^{6}$ ) Daarbij wees hij er terecht op, dat de zorg voor grotere publiciteit, die Sanders als de voornaamste taak van de Vennootschapskamer zag, nog geen remedie is tegen kwalen als een N.V. Gemeenschappelijk Bezit en een Administratiekantoor. Zijn voornaamste bezwaren zijn de volgende:

a. Niemand is gedwongen zijn vermogen in aandelen van publieke naamloze vennootschappen te beleggen; door zich te onthouden van belegging in aandelen van n.v.-en, die het niet nauw nemen met de publicatieplicht, dwingt men deze vanzelf tot grotere openbaarheid.

b. Indien behoef te bestaat aan corrigerend optreden, is er reeds een orgaan dat die taak kan vervullen, t.w. de Vereeniging voor den Effectenhandel.

c. Schaarsheid van publiciteit heeft nadelen; overruime publiciteit schaadt de belangen van de belegger nog meer.

Daarnaast noemt Schadee in de tekst van zijn artikel nog terloops enkele waarborgen tegen de uitholling van de macht van de aandeelhouder. Zo zou de persoon van de commissaris van meer betekenis zijn voor de aandeelhouder-belegger dan de uitoefening van het stemrecht; er bestaat de waarborg van accountantscontrole: in het verslag van de accountant aan de commissarissen kunnen eventuele opmerkingen van de accountant door de laatsten niet naast zich neergelegd worden. Verder stelt hij, dat de oligarchie veelal een noodzakelijke bescherming inhoudt van de belangen van de onderneming resp. van alle aandeelhouders voorzover deze tegengesteld zouden zijn aan de belangen van de meerderheid in de aandeelhoudersvergadering. De vergelijking met de Verzekeringskamer en met de in de Verenigde Staten bestaande regelingen gaat volgens hem om allerlei redenen mank en zelfs in geval er misstanden zouden bestaan acht hij een kostbaar overheidslichaam niet nodig om daar een einde aan te maken. Tenslotte: het overtuigend bewijs dat er een Vennootschapskamer nodig zou zijn is ook z.i. nog niet geleverd. Op de door Schadee tegen de Vennootschapskamer in geweer gebrachte bedenkingen kom ik in een volgende paragraaf terug. Ik wil hier nog even doorgaan over de ontwikkeling van de opvattingen over de Vennootschapskamer. Vermelding verdient n.l., dat in een onlangs in de Algemene Vergadering van de Broederschap der Candidaat-Notarissen uitgebracht prae-advies door Mr.G.H.A. Grosheide en $A$. M. Vroom eveneens tegen de instelling van een Vennootschapskamer is geopponeerd. ${ }^{7}$ ) $M r$. Grosheide is tégen een Vennootschapskamer; verplichte accountantscontrole acht hij niet aanvaardbaar zonder wijziging van het vennootschapsstelsel. Een herziening van het vennootschapsrecht acht hij niet spoedeisend. $M r$. Vroom vraagt zich, op het voetspoor van Schadee c.s., af of de bestaande toestand reden geeft tot een zo ingrijpende maatregel als het invoeren van een Vennootschapskamer. Bovendien vreest hij dat, als eenmaal een Vennootschapskamer bestaat, deze zijn bemoeiingen te ver kan gaan uitstrekken.

\section{Par. 3. Het rapport van de Wiardi Beckmanstichting over de Vennootschaps- kamer.}

Het geluid, dat het rapport van de Wiardi Beckmanstichting laat horen is geheel anders. Zoals eigenlijk niet anders te verwachten was, wordt uit deze

6) Mr. A. Schadee, „Een Vennootschapskamer?” N.V. XXXII, april 1954, pag. 1/4.

7) „Machtsverhoudingen in Naamloze Vennootschappen”, prae-adviezen uitgebracht door $M r$. G. H. A. Grosheide en $A . M$. Vroom in de Algemene vergadering van de Broederschap der Candidaat-Notarissen, op 29 mei 1959. 
hoek instelling van een Vennootschapskamer wenselijk geacht. In navolging van de SEC zou deze een gering aantal leden kunnen hebben, b.v. 5, door de Kroon te benoemen. Hoofdtaak zou zijn het toezien op naleving van de verslaggevingsvoorschriften en de bepalingen inzake het emissieprospectus. Wat het eerste betreft: alle n.v.-en, dus zowel open als besloten, met een aandelenkapitaal van meer dan $f$ 500.000, - zouden aan controle van de Vennootschapskamer onderworpen dienen te worden; dit zouden dan ongeveer, op basis van de CBS-statistiek 19521955 , een kleine 1600 vennootschappen zijn die ruim $80 \%$ van het aandelenvermogen van alle Nederlandse n.v.-en bezitten.

Jaarlijks zou de Vennootschapskamer, analoog aan hetgeen de Verzekeringskamer doet, $10 \%$ van de betrokken naamloze vennootschappen in een diepgaand onderzoek dienen te betrekken, teneinde hun jaarrekeningen te controleren.

Wat het emissieprospectus betreft: de daarin te verstrekken gegevens moeten gedetailleerd worden voorgeschreven. Uitgifte van het prospectus kan alleen geschieden na verkregen toestemming - een verklaring van geen bezwaar - van de Vennootschapskamer. Deze onderzoekt vóór publicatie elk prospectus; ongemotiveerde toekomstverwachtingen dienen daaruit te worden geweerd.

Tenslotte zou de Vennootschapskamer nog een taak hebben in geval van fusie of financiële reorganisatie van naamloze vennootschappen, met name ten aanzien van hetgeen door de betreffende vennootschappen te dien aanzien wordt gepubliceerd.

Verder wordt het nodig geacht publicatie van een accountantsverklaring bij de jaarrekening dwingend voor te schrijven. Hangende de wettelijke regeling van het accountantsberoep wordt als tijdelijke overgangsmaatregel voorgesteld, althans voor de grootste naamloze vennootschappen, het certificeren van de jaarstukken door accountants verplicht te stellen; t.a.v. de benoeming van de accountant wil het rapport een verklaring van geen bezwaar in deze overgangstijd, af te geven door de Vennootschapskamer, verplicht stellen.

Dit is , in a nutshell" hetgeen het rapport van de Wiardi Beckmanstichting met betrekking tot de Vennootschapskamer opmerkt. ${ }^{8}$ ) Hierbij moet wel worden bedacht, dat de instelling van een Vennootschapskamer maar een deel is van hetgeen de commissie wenselijk acht om de aandeelhoudersvergadering weer aan betekenis te doen winnen en aan deze vergadering, werknemers en publiek meer inzicht in en toezicht op de bedrijfsgesties te verschaffen.

De vraag rijst of de bezwaren tegen instelling van een Vennootschapskamer, die van diverse zijden worden vernomen en in het artikel van Schadee uitvoerig zijn verwoord, ook gelden voor de voorstellen die door de commissie van de Wiardi Beckmanstichting zijn gedaan. Deze bezwaren dienen daartoe eerst op hun steekhoudendheid te worden bezien; mocht blijken, dat veel van de gehoorde kritiek ongegrond is, dan zou mogelijk ook veel kritiek tegen het plan van de Wiardi Beckmanstichting al bij voorbaat de wind uit de zeilen zijn genomen. Wat nu de bezwaren betreft, waarmee Schadee komt aandragen: veel hiervan lijkt me niet gefundeerd. Het onder a. in het voorgaande aangehaalde argument van Schadee, dat men nu eenmaal niet gedwongen is, zijn vermogen in aandelen te beleggen, is op zijn minst veel te algemeen gesteld. $\mathrm{Na}$ al hetgeen in de financiële pers over het onderwerp is betoogd kan ik me ontslagen achten van het geven van het bewijs, dat de publicaties van naamloze vennootschappen in Nederland in een aantal

8) O.c. hfdst. V, vooral pag. 129 e.v. Op pag. 163 wordt nog een nieuwe taak voor de V.K. aangegeven: toezicht op de naleving $\operatorname{van}$ voorschriften m.b.t. administratiekantoren in de zin van het rapport van de commissie-Hellema. 
gevallen onvoldoende zijn. Zouden de potentiële aandeelhouders inderdaad alleen deelnemen in vennootschappen, die in hun gepubliceerde jaarstukken voldoende inzicht aan de aandeelhouders geven, dan zou er slechts een beperkt aantal naamloze vennootschappen overblijven waarin zou kunnen worden deelgenomen. Dat zou op zichzelf elke n.v. die ,open" zou willen gaan kunnen dwingen, voldoende openbaarheid te betrachten. Maar het is nu eenmaal zo, dat aandeelhouders primair naar het te verkrijgen inkomen kijken, zelfs die aandeelhouders, die een langduriger binding met de vennootschap op prijs stellen. De aandeelhouders vormen geen homogene massa van individuen, die zorgvuldig hun kansen berekenen, veeleer is het een ongedifferentieerde groep van beleggers, die op grond van hun inkomen in het verleden met bepaalde fondsen behaald, beslissen, waarin ze in de toekomst hun vermogen zullen beleggen. Van de groep als geheel kan men, zonder een enkele individuele aandeelhouder tekort te doen, zeggen, dat verlangen naar meer inzicht in financiële positie en resultaten van een bepaald bedrijf niet als reëel wordt gevoeld. De oorzaken van een dergelijke, naar mijn mening onmiskenbare, groepsgeest laat ik hier in het midden; mogelijk kunnen de psychologie of sociologie hier een verklaring voor geven. Het feit bestaat nu eenmaal. Dat in de groep beleggers ook een aantal belangrijke ,beroepsbeleggers" thuishoort, te weten de institutionele beleggers (verzekeringsmaatschappijen, spaarbanken, pensioenfondsen, bedrijfsverenigingen enz. naast beleggingsdepots) doet aan de constatering geen afbreuk. Dergelijke instellingen beleggen over het algemeen in fondsen van eerste klasse ondernemingen. Het moet echter worden betwijfeld, of ze in hun overwegingen verder gaan dan de ,,doorsnee-aandeelhouder": in feite staan ook hun niet meer gegevens ter beschikking dan de weinige, die uit gepubliceerde jaarverslagen blijken, al is het niet uitgesloten dat door institutionele beleggers nog iets wordt gedaan aan cijferbeoordeling en aan analyse van verschillende cijferverhoudingen.

Uit het bovenstaande meen ik te kunnen afleiden, dat de belegger niet zo vrij is als Schadee c.s. ons wil doen geloven. Zolang de beleggers als groep ondeskundig en indifferent blijven en dientengevolge een betere verslaggeving niet als conditio sine qua non voor het beleggen zien, zal deze er ook zonder meer niet komen. De stelling van Schadee zou dan ook moeten luiden: zolang beleggers niet hetzij door gezamenlijke actie, hetzij door ingrijpen van een daartoe ingestelde instantie, de naamloze vennootschappen tot grotere openbaarheid in de verslaggeving dwingen, zullen zij, voorzover zij geen andere beleggingsmogelijkheden hebben, in dezelfde mate als thans in naamloze vennootschappen moeten deelnemen.

Wat het onder b. door Schadee gestelde betreft; ook hierop valt wel het een en ander af te dingen. De Vereeniging voor den Effectenhandel is n.l. een vereniging van belanghebbenden bij de effectenhandel. Indien men van een dergelijke vereniging zou verlangen dat zij allerlei bepalingen met betrekking tot de verslaggeving in het leven riep en op de nakoming ervan toezicht uitoefende, dan betekent dat het stellen van een vrij onmogelijke eis. Men zou dan verwachten dat belanghebbenden bij de effectenhandel zich zouden beijveren om door allerlei bepalingen de effectenhandel te gaan bemoeilijken. Ik geloof niet dat men iets dergelijks redelijkerwijs mag eisen. De praktijk wijst uit - o.m. wat de lotgevallen betreft van het rapport-Hellema - dat de V.v.d.E. aanbevelingen van commissies, uit haar midden ingesteld, slechts schoorvoetend en met de nodige slagen om de arm pleegt te volgen, zich bewust van de weerstanden die de effectenhandel daartegen heeft. De goede bedoelingen van de Vereeniging voor den Effectenhandel hoeft men niet in twijfel trekken, wel de wenselijkheid, dat deze instantie c.q. het bestuur ervan 
geroepen zou moeten zijn om door allerlei ingrijpende maatregelen eigen positie te ondergraven. Hiervoor heeft men geen groep van belanghebbenden, maar een boven de partijen staand lichaam nodig.

Wat punt c. betreft: hier ben ik geneigd Schadee enigszins te volgen, al is zijn opmerking wat te algemeen gesteld. Het hangt n.l. erg van het betreffende geval af, of openbaarheid al of niet schadelijk is. Beter zou men kunnen stellen, dat in sommige gevallen openbaarheid meer schade zou kunnen toebrengen aan de onderneming dan een beperkte verschaffing van gegevens. ${ }^{9}$ ) Het zou voor bepaalde bedrijven als een boemerang werken als ze concurrenten en afnemers te wijs zouden maken. Dergelijke gevallen heeft de commissie van de WB-stichting ook voorzien; op blz. 124 van het rapport wil de commissie dan ook in navolging van hetgeen in Engeland gebruikelijk is, de mogelijkheid scheppen door de minister van economische zaken aan daarvoor in aanmerking komende ondernemingen dispensatie van bepaalde publikatieverplichtingen te laten verlenen. De Vennootschapskamer zou dan wel inzage krijgen van de niet voor publikatie bestemde gegevens, zodat deze kan beoordelen of er terecht een beroep op dispensatie wordt gedaan.

De verdere argumentatie van Schadee is naar mijn mening evenmin steekhoudend. Zo stelt hij, dat nog niet bewezen is, dat een Vennootschapskamer nodig is. Hij beroept zich daar o.m. op het feit, dat er weinig omvangrijke déconfitures van naamloze vennootschappen zijn voorgekomen in Nederland. Dat is juist. Ik wil dat niet afdoen met de opmerking, dat men niet moet wachten met het dempen van de put voor het kalf is verdronken. Ik betwijfel of het kalf ooit zal verdrinken! Veel ernstiger acht ik nl. het feit, dat, waar nog steeds een groot aantal vennootschappen niet door een openbaar accountant wordt gecontroleerd, bij deze vennootschappen onder het huidige vennootschapsbestel niet aan het licht behoeft te komen of en zo ja, in welke mate, ongerechtigheden plaats grijpen. Het is heden ten dage denkbaar, dat een dergelijke naamloze vennootschap vrij belangrijke verliezen lijdt, of volkomen verkeerde investeringen pleegt, die niet merkbaar worden aan de buitenwacht. Zolang men daar nog verliezen zou kunnen afboeken van geheime reserves, waarvan - uiteraard - het publiek geen notie heeft, zolang daar nog „Fehlinvestierungen” en de gevolgen daarvan weggewerkt kunnen worden in dat deel van de resultaten, dat „vóór de streep”, d.w.z. binnen het nietgespecificeerde ,saldo exploitatierekening” ligt, zolang is het nog mogelijk dat er ,interne" déconfitures plaats grijpen, waar niemand behalve insiders enige weet van heeft. Er is dan ook geen aanleiding een put te dempen, omdat niemand van het verdronken kalf weet heeft!

De ,enorme waarborg”, die Schadee in de controle van de onafhankelijke accountant ziet, kan dus, zoals gezegd, alleen dáár bestaan waar een accountant is aangesteld en dan nog alleen maar voorzover deze accountant een goedkeurende verklaring geeft. Tal van ondernemingsleidingen hebben bij gebreke aan het bestaan van een verplichte accountantscontrole vrij spel. ${ }^{10}$ ) En voorts kan men verwachten, dat indien de accountant geen goedkeurende verklaring wenst te

9) Elders heb ik betoogd, dat niet a priori mag worden gesteld dat openbaarheid zonder gevaar is; de belangen van de onderneming dienen tegen die van anderen te worden afgewogen en de juiste dosering vastgesteld. (,De verslaggeving van de naamloze vennootschap", maandblad voor bedrijfsadministratie, april 1954, pag. 57/60.)

10) Blijkens een onderzoek door mij ingesteld naar het voorkomen van accountantsverklaringen in jaarverslagen van n.v.-en met aan de beurs genoteerde aandelen, over 1957, bleek dat van 361 n.v.-en er bij 63 geen melding van accountantscontrole werd gemaakt. Hieronder kwamen grote n.v.-en voor. 
geven, zijn afkeurende verklaring niet zal worden gepubliceerd. ${ }^{11}$ ) Er bestaat nu eenmaal geen wettelijke verplichting voor de onderneming om coûte que coûte de accountantsverklaring te publiceren. Alleen in het zeldzame en misschien wel nietbestaande geval dat een accountant door aandeelhouders-outsiders zou zijn aangesteld zou te verwachten zijn dat een afkeurende verklaring van deze accountant het publiek kan bereiken, voorzover het althans een open naamloze vennootschap betreft.

Zolang de huidige wetgeving op de naamloze vennootschap het nog mogelijk maakt, dat, althans waar accountantscontrole ontbreekt, het grofste gebrek aan ondernemersinzicht en het meest ontstellende falen van een ondernemingsleiding in een aantal gevallen straffeloos kan worden gecamoufleerd en dat een accountant in een aantal gevallen met dank voor de bewezen diensten kan worden weggezonden als hij een afkeurende verklaring afgeeft, zolang is het niet meer nodig een „bewijs" te vragen dat een Vennootschapskamer op zijn plaats is. Uit het ontbreken van een ,voldoend aantal" déconfitures in het verleden mag nl. niet worden geconcludeerd, dat alles nu pais en vrèe is in Vennootschapsland.

Over de verplichte accountantscontrole heeft het Rapport van de Wiardi Beckmanstichting zich, als reeds gezegd, positief uitgelaten. Daarbij ${ }^{12}$ ) wordt melding gemaakt van het feit, dat van accountantszijde instelling van verplichte accountantscontrole bepleit wordt. Van hoe groot belang e.e.a. ook kan worden geacht, het komt me niet juist voor als inderdaad van accountantszijde propaganda voor de verplichte accountantscontrole wordt gemaakt. Van die kant is men waarschijnlijk wel vrij algemeen overtuigd van de noodzaak de positie van de accountant te versterken. Maar als „,belanghebbende” kan men zich beter van een pleidooi onthouden; het maatschappelijk verkeer dient de noodzaak van instelling van een verplichte accountantscontrole in te zien. Als accountant heeft men ongetwijfeld de taak om in het algemeen het maatschappelijk verkeer van de waarde en de betekenis van accountantscontrole bewust te doen worden. Dat mag echter niet zover gaan dat een oratio pro domo wordt gehouden of de schijn daarvan wordt gewekt. Daarom zal hier ook niet worden ingegaan op de vraag of verplichte accountantscontrole wellicht het instellen van een Vennootschapskamer overbodig zou kunnen maken.

Aan het slot van dit artikel meen ik te moeten vaststellen dat de Wiardi Beckmanstichting belangrijk werk heeft gedaan door de idee van een Vennootschapskamer nieuw leven in te blazen. Het instellen van een dergelijk lichaam zal, verre van het verantwoordelijkheidsgevoel van de betrokken ondernemingsleidingen te verminderen, juist een prikkel vormen om een verantwoord beleid te voeren en van het gevoerde beleid een duidelijk inzicht te geven. Of dat inzicht volledig „buiten de deur" moet worden gebracht, is een vraag die van geval tot geval beantwoord zal moeten worden. Maar het zou een grote stap vooruit zijn als een Vennootschapskamer voor het algemeen belang zou waken door als „meer dan verstandige leek" kennis van de resultaten van het gevoerde beleid en van de financiële positie van ondernemingen te kunnen nemen. En dat ,algemeen belang” is dan ook het belang van de bonafide ondernemers, die niet gebaat kunnen zijn met praktijken van eventuele malafide soortgenoten, b.v. bij het aantrekken van nieuw vermogen. Het is daarom te hopen dat de idee van een Vennootschapskamer ditmaal het volle pond zal krijgen.

11) VgI. Prof. T. Keuzenkamp, „De accountantsverklaring bij de jaarrekening”, in „Maatschappijbelangen", mei 1959 no. 5, pag. 233: „Zolang er geen publikatieplicht bestaat zou het op de weg van de finantiële pers kunnen liggen om meer aandacht te besteden aan het al of niet voorkomen en het verdwijnen van accountantsverklaringen in gepubliceerde jaarverslagen. Helaas heeft ook deze daarvoor blijkbaar geen belangstelling."

12) o.c. pag. 126. 